only adequate measure to conserve the fishery is to set some limit to the amount of fishing. The alternative is what we have in fact seen, the history of boys not being so unwise as to join an industry where unexampled hardship is coupled with such unattractive prospects.

However, the moment you agree to set a limit to fishing power, you find that you have in practice taken on responsibility for the way of life of the fishermen-and that brings me to the social consequence of the natural law of the stock of fish. Here it seems to me that Huxley would be on my side. $\mathrm{He}$ had such a practical and clear-sighted appreciation of arrangements as they affected people, as he showed in his statement of the position of the crofters, in the passage that I have quoted.

No one likes ordering the lives of other people, but control forces us either to order them or to disorder them ; and to order them seems to me to involve fostering all the qualities that we admire in them. Thus we could foster individual enterprise, inventiveness, skill, technical improvement, better conditions, and any other thing that we know to be good.

Thus it seems to me, at any rate, fishery science has in these sixty years since the Exhibition brought in the power of knowledge. I do not suppose that we have more than a first approximation to the truth yet-in many departments of the science-but we have that approximation established beyond any doubt whatever, and we know exactly what has to be done.

In 1868 the scientific attitude liberated the fishery from unnecessary regulations, and allowed it to become great. But the industry has now reached the bounds set by Nature, and science, which allowed the child to grow to manhood, has now the knowledge to say what is proper in a mature industry, dependent on a natural resource.

\section{SYNTHETIC RUBBER PROBLEMS}

THE chairman of the Division of Rubber Chemistry of the American Chemical Society, at the spring meeting of the. Division in April in New York City, well said that while the achievements of rubber technologists with natural rubber in a hundred years of progress are a subject for just pride, the actual production work with synthetic rubber in less than a hundred weeks is nothing short of a miracle.

Nevertheless, the processing problems involved in using $G R-S$, which is the butadiene-styrene polymer mass-produced in the United States to replace the million tons of natural rubber in enemy hands, are still numerous, difficult, and of serious significance to the available output and service life of the products. There is ample evidence of this in the papers read before the Rubber Division, the great majority being devoted, directly or indirectly, to $G R-S$ processing difficulties.

Six to twelve months ago, the rubber manufacturer's primary anxiety was to masticate, plasticize and render self-adhesive or 'tacky' the $G R-S$ mixings from which rubber articles are built or moulded. No entirely satisfactory methods are yet available for this work, but provisional practical processes have been made generally known with which we can 'make do' until better are found. The relief from this anxiety has transferred attention to vulcanization difficulties, of which the variability aspect is the worst. A paper by F. E. Rupert and F. W. Gage reveals that atmospheric humidity is a factor of the first importance in the question. Exposure of unvulcanized mixings to increased humidity and increased length of exposure increases the rate of vulcanization by as much as one hundred per cent. Other evidence has been accumulating for some time, all indicating that very exact control of the water content of $G R-S$ mixings is of vital practical importance.

Revolutionary ideas on the acceleration of vulcanization were given in a paper by $\mathbf{A}$. $\mathbf{A}$. Somerville in announcing two new copper compounds as being several times as active as conventional accelerators. So little as 0.01 per cent by weight of ordinary 300 mesh copper powder added to a $G R-S$ mix will shorten the vulcanization period by half, and the new copper compounds are even more effective. Moreover, instead of the rapid perishing frequently encountered in natural rubber contaminated with copper, $G R-S$ articles containing the copper accelerators actually have increased resistance to ageing. Sixteen other metals failed to show these remarkable effects.

Equally novel was a paper read by G. M. Wolf, T. E. Deger, H. I. Cramer, and C. C. de Hilster, on the successful use of a new class of vulcanizing agents -alkyl phenol sulphides, in particular $p$-tertiaryamylphenol disulphide. These agents are claimed to possess two very important advantages over sulphur in that (1) they impart some tackiness to $G R-S$ mixings, and (2) they give products with outstanding resistance to deterioration by heat. The heating up of large tyres in use, which is the most serious of the unsolved production problems, since the only remedy at present is to use up the scanty stocks of natural rubber, may at least be ameliorated by the application of these sulphide vulcanizers. The heat build-up problem was touched upon, also, in a paper by G. M. Massie and A. E. Warner, who report that the use of a non-persistent accelerator, for example, a substituted lead dithiocarbamate, much reduces the tendency of $G R-S$ to stiffen due to service heat, especially if diphenyl-ethylenediamine is used in the mixing.

A third paper, by A. R. Lukens, was also associated with the heat-stiffening question. It was pointed out that the trouble arises mainly from the presence in $G R-S$ tyres of liberal loadings of very fine particle carbon blacks. Such loadings have become customary since the other reinforcing agents often used in natural rubber-zinc oxide, magnesium carbonate, whiting, for example-fail to confer any improvement in $G R-S$. It has now been shown, however, that mineral pigments such as those noted can be prepared in much more finely divided forms than hitherto, with the result that they considerably reinforce $G R-S$, but do not cause heat build-up. Mixings containing lower proportions of carbon black and these new fillers may well be a great improvement on to-day's practice.

Other papers at the meeting dealt with various standard problems, adding much valuable information without conspicuous novelties. Reference may be made in conclusion to an account by R. A. Emmett of an interesting range of raw materials comprising blends of various butadiene rubbers with plasticized polyvinyl chloride. Both vulcanizable and nonvulcanizable plastics have been developed in this range. They possess the good qualities of both components and provide a much-needed economy in rubber in a wide variety of applications. 